\title{
OFICINA PEDAGÓGICA SOBRE LATERALIDADE E ORIENTAÇÃO: UMA EXPERIÊNCIA COM ALUNOS DO ENSINO FUNDAMENTAL
}

\author{
Guilherme Moreira da Silva ${ }^{(a)}$ Roberto Cassol ${ }^{\left({ }^{(b)}\right.}$ Maurício Rizzatti ${ }^{(\mathrm{c})}$ Natália Lampert Batista \\ (d)
}

\author{
(a) Acadêmico do Curso de Geografia, Universidade Federal de Santa Maria, E-mail: \\ guilhermems2010@gmail.com \\ (b) Prof. Dr. do Departamento de Geociências, Universidade Federal de Santa Maria, E-mail: \\ rtocassol@gmail.com \\ (c) Mestrando em Geografia, Universidade Federal de Santa Maria, E-mail: geo.mauricio.rizzatti@gmail.com \\ (d) Doutoranda em Geografia, Universidade Federal de Santa Maria. E-mail: natilbaista3@gmail.com
}

\section{EIXO: GEOGRAFIA FÍSICA - CURRÍCULO, FORMAÇÃO E PRÁTICAS DE ENSINO}

\begin{abstract}
Resumo
O presente artigo tem como objetivo geral apresentar e relatar uma Oficina Pedagógica realizada com alunos do Ensino Fundamental, sobre noções cartográficas de Lateralidade e Orientação. A proposta foi realizada em três momentos. Primeiramente ocorreu a apresentação do objetivo da atividade e a realizou-se uma contextualização sobre o assunto com os alunos, Após, realizou-se uma atividade com a turma em relação às noções de Lateralidade ("Tabuleiro Vivo") - enfatizando a posição do ponto de referência. Por fim, ocorreu a realização da atividade referente à orientação espacial, denominada "Caça ao Tesouro". Com a proposta, pode-se observar que os educandos que participaram da Oficina demonstrando interesse e motivação, bem como se notou a importância do ensino em Lateralidade e Orientação na geografia, visto que as mesmas tornam-se promissoras no auxílio ao homem e sua relação com os elementos presentes na superfície terrestre.
\end{abstract}

Palavras-chave: Ensino de Geografia. Cartografia Escolar. Prática Pedagógica.

\section{Introdução}

A cartografia busca por meio da espacialização dos fenômenos naturais e geográficos, representá-los em um mapa, carta ou em outras formas de representação gráfica (físicos, socioeconômicos, culturais). No âmbito escolar, a cartografia está cada vez mais ligada ao ensino em Geografia, em razão da sua importância no auxílio da construção dos conhecimentos geográficos, que instigam ao educando habilidades na leitura do mundo por meio de suas representações (PASSINI, 1994).

Rizzatti (2016), ao abordar o ensino em geografia, aponta que

Nesse sentido, a geografia não deve ser vista como uma disciplina escolar simplória, enfadonha e de caráter enciclopédico, mas como uma ciência que é capaz de formar cidadãos, de analisar e pensar os fenômenos sociais, físicos e naturais que ocorrem diariamente na sociedade. É uma área do 
conhecimento de extrema relevância, pois permite compreender o espaço onde vivemos, ou seja, a relação da natureza com a sociedade. (RIZZATTI, 2016, p. 17).

A partir do exposto, percebe-se o grande valor do estudo em Geografia, bem como sua contribuição aos educandos que ponderam seus conhecimentos. Desse modo, a Cartografia Escolar que abrange os estudos geográficos sempre esteve ligada a formação e compreensão do espaço, servindo como embalsamento a análise e entendimento dos fenômenos ocorrentes na superfície terrestre, como conceber a leitura e manejo na arte e técnica de representar esses elementos.

Com a origem da Geografia Crítica, a práxis no ensino em geografia se voltou em abordar e privilegiar a realidade do educando, bem como estar presente em suas multifaces culturais e sociais (SOUZA, 2013). Dessa maneira, a linguagem cartográfica é atribuída de valor significativo ao ensino geográfico, visto que os conceitos atribuídos a sua alfabetização (localização, orientação, território) se inicia pelo conhecimento prévio do educando, como sua relação com os fenômenos e objetos presentes em seu espaço vivido.

A linguagem cartográfica utilizada nas aulas de geografia, proporciona também ao aluno uma visão de que o mesmo é sujeito da organização espacial e suas transformações ocorrentes na superfície terrestre. Os conceitos conexos à localização e lugar abordados ao cotidiano do aluno, possibilita que ele compreenda esses conceitos, e consiga interpretá-los em espaços maiores, o qual é atribuído a uma leitura sistematizada das múltiplas escalas de análise, bem como a relação dos fenômenos presentes nessas realidades.

Do mesmo modo, torna-se importante que o educador, realize atividades e utilize uma pedagogia que instigue ao educando, de forma criadora, em aproveitar e conceber essa metodologia de ensino, a qual permite que o aluno ultrapasse a condição de interprete de mapas acrítico e torne-se leitor e mapeador consciente de sua realidade e de seu cotidiano como aponta Simielli (1999). Assim, os conceitos que permeiam a alfabetização cartográfica no ensino em Geografia, apresenta ao aluno uma maior compreensão na leitura do mundo e do espaço vivido, através de uma leitura crítica decorrente a formação cidadã.

Sobre os conceitos que permeiam a alfabetização cartográfica, Simielli (1994) aponta que

Algumas noções são básicas na alfabetização cartográfica, tais como: a visão oblíqua e a visão vertical, a imagem tridimensional e a imagem bidimensional, o alfabeto cartográfico (ponto, linha e área), a construção da noção de legenda, a proporção e a escala, a lateralidade, referências e orientação espacial. O desenvolvimento dessas noções contribui para a desmistificação da cartografia como propositora de mapas prontos e acabados no ensino fundamental e médio (SIMIELLI, 1994, p.77).

Diante disso, verifica-se a importância em trabalhar noções de Lateralidade e Orientação (espacial) com os educandos, em razão das mesmas serem contribuintes na construção do ensino aprendizagem 
geográfico aos alunos. O uso de atividades práticas no ensino de lateralidade e orientação auxilia no entendimento dos conhecimentos provenientes das mesmas, visto que através de atividades práticas vinculadas no cotidiano do aluno, o estudante aprende a se localizar, orientar e posicionar-se no espaço (FRANCISCHETT, 2005, p.136).

Sobre a temática, Francischett (2002), reflete que

As dificuldades em torno da aprendizagem de localização e orientação provém da faltam de hábito de utilizarem, na prática cotidiana, estes conceitos. Na escola, quando muito, são feios alguns exercícios no mapa, mesmo sem este estar devidamente orientado. Como é possível gostar do que não conhecemos? (FRANCISCHETT, 2002, p.60).

Com base nisso, o presente artigo tem como objetivo geral relatar uma oficina pedagógica realizada com alunos do Ensino Fundamental, sobre noções cartográficas de Lateralidade e Orientação. Para aprofundar e detalhar o objetivo apresentado, tem-se os específicos: compreender o que é lateralidade e orientação geográfica, bem como sua importância no ensino em geografia; verificar a compreensão dos educandos sobre as noções de lateralidade e os meios de orientação durante as atividades didáticas; identificar a motivação dos alunos ao realizar as atividades explorando o ambiente externo da escola, de acordo com seus objetos e espaço.

\section{Metodologia}

A oficina pedagógica sobre Lateralidade e Orientação geográfica foi planejada e desenvolvida na disciplina Geografia e Ensino I (GCC182) do curso de Geografia (Licenciatura Plena) da Universidade Federal de Santa Maria. Aplicou-se a atividade na Escola Municipal de Ensino Fundamental Junto ao CAIC "Luizinho de Grandi" no município de Santa Maria (RS), cuja localização é ilustrada na Figura 1 , com discentes do $6^{\circ}$ ano. 


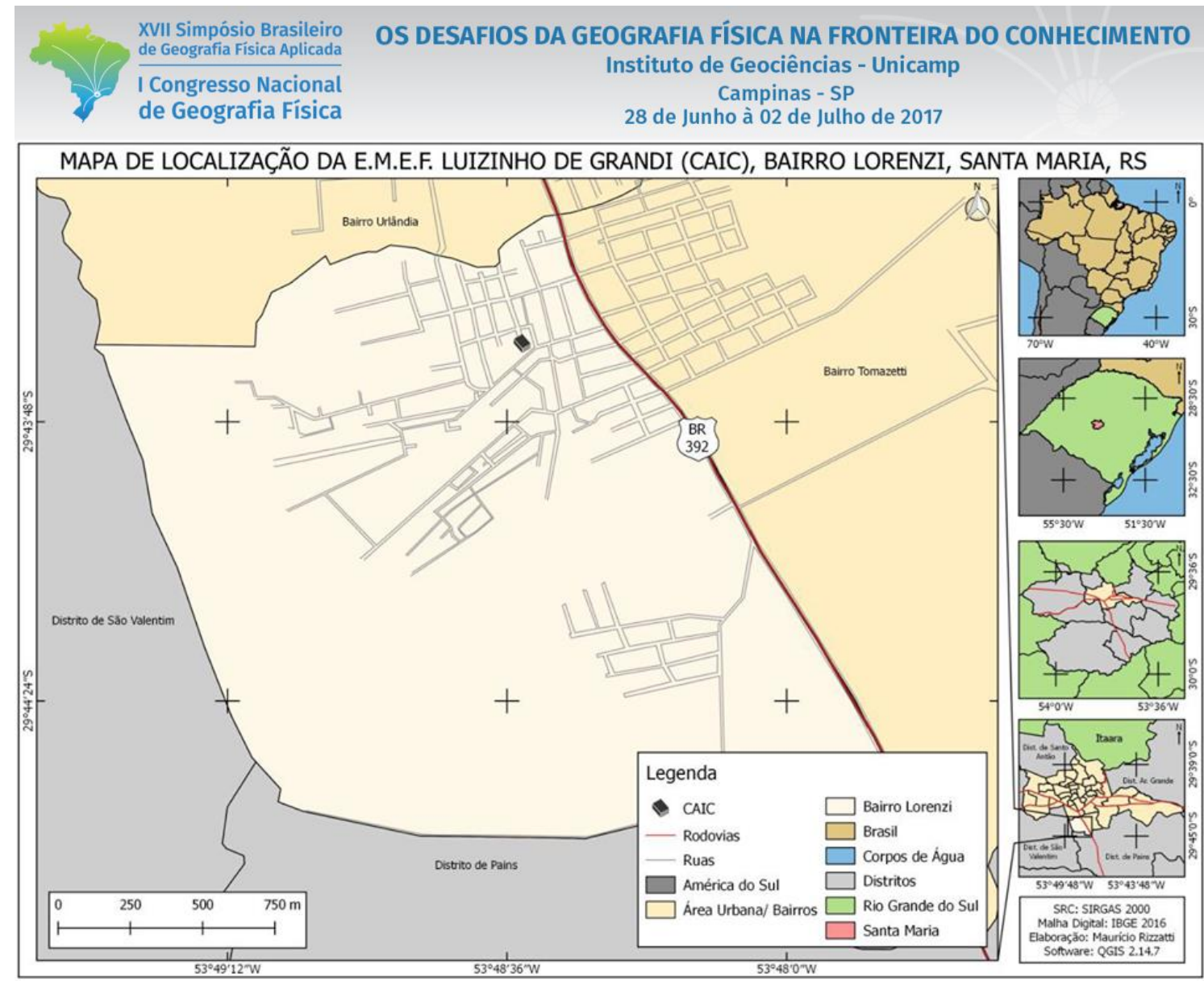

Figura 1 - Mapa de Localização da E.M.E.F. Luizinho de Grandi (CAIC).

Fonte: RIZZATTI, 2016.

No primeiro momento, fez-se um levantamento em referenciais teóricos, a fim de aprofundar o conhecimento pertinente à Lateralidade e Orientação, bem como estratégias de fundamentar os mesmos em atividades práticas e lúdicas. Após, realizou-se uma visita na escola onde atividade foi aplicada, para que pudesse ser feito uma análise sobre o espaço de convivência dos educandos no seu ambiente escolar, a fim de monitorar possibilidades para ser realizadas sequências didáticas de modo que envolvesse esse espaço integrador entre os alunos.

Nessa ocasião, tornou-se importante a visita na escola, visto que como função de educador, é necessário estar atento a realidade que tange a vivência de seus alunos, para que possa ser aproveitado os conhecimentos e saberes que os mesmos possuem perante a sua realidade (FREIRE, 1996).

Posteriormente a visita na escola, para a construção da Oficina, foram criadas três atividades práticas que corresponderam à aplicação das noções de Lateralidade e Orientação com os alunos na Escola. Essas atividades além de abranger o propósito em contextualizar os conhecimentos a realidade do aluno, teve como objetivo integrar os alunos entre si, fazendo com que os mesmos pudessem trabalhar em equipe durante o desenvolvimento das atividades a qual, através dessa perspectiva, eles pudessem dividir seus conhecimentos prévios referente aos conteúdos trabalhados de forma colaborativa. 
O primeiro recurso consistiu em realizar uma contextualização sobre Lateralidade com os educandos.

Nesse momento, os estudantes deveriam responder alguns questionamentos sobre noções da Lateralidade corporal (esquerda, direita, frente e costas), como por exemplo "Qual o seu braço direito?", "Que colega está a sua direita?", "Ficando de costas, o colega que estava a sua direita, continua estando na mesma?", "Qual objeto encontra-se a direita de você?”.

Essa dinâmica teve como proposito que o educando pudesse analisar que o seu corpo é um ponto de referência e, conforme se vira de um lado para outro, altera-se a posição dos objetos ao seu redor, atribuindo esses conhecimentos para a Orientação. Freire (1994, p. 14), aponta que "a cada início de ano letivo, por ocasião da matrícula, também o corpo seja matriculado", ou seja, é necessário proporcionar a criança jogos e brincadeiras a qual elas podem se expressar através de seu corpo, a qual além de atribuir atividade lúdica a criança, visto que ela pode construir maior aprendizagem na prática, do que estar dentro de uma sala de aula imóvel e quieta.

O segundo exercício consistiu em aplicar uma dinâmica sobre Orientação. Essa atividade denominada "Tabuleiro Vivo", trouxe noções dos pontos cardeais e colaterais ao seu desenvolvimento, interligados com as noções de Lateralidade, estes trabalhados na primeira atividade.

A terceira atividade, aproveitando a estrutura física da escola, consistiu em proporcionar aos alunos um jogo referente ao "Caça ao tesouro", onde os mesmos deveriam, através de pistas expostas em um mapa, encontrar alguns pontos distribuídos pela área externa da escola. Essas pistas que comandavam os alunos ao encontro desses pontos, foram criadas com o objetivo de analisar a percepção espacial que os educandos tinham perante a escola, juntamente com os objetos integradores desse espaço, e com as noções atribuídas nas atividades anteriores, Orientação e Lateralidade (corpo do aluno em relação aos objetos pertencentes a escola).

Além disso, a oficina foi elaborada com a contribuição de instrumentos e meios de orientação existentes, que ao longo da história foram responsáveis ao homem se orientar e localizar na superfície terrestre. Desse modo, foi utilizado como recurso metodológico, o aparelho GPS, Bússola e imagens referente à Orientação pelos astros, para a contextualização desses meios, referente a noção de Orientação geográfica.

\section{Resultados}

$\mathrm{Na}$ primeira atividade, referente a contextualização sobre Lateralidade, pode-se observar que os educandos demonstraram interesse e envolvimento em realizá-la, bem como demonstraram compreender a temática que estava sendo desenvolvida. No decorrer da mesma, dividiu-se a em dois momentos, baseados na participação dos educandos. Por exemplo, caso houvesse um aumento da interação dos estudantes com a explicação, acrescia-se gradativamente com exemplos e questionamentos pertinentes a Orientação, para uma melhor fixação teórica do tema em questão. 
Primeiramente, perguntou-se aos discentes, sobre "O que vocês entendem por se orientar?". Diante disso, observou-se que os mesmos sentiram retraídos em responder à pergunta. Assim, foi explicado que uma das formas promissoras da Orientação no espaço, é através do corpo, a qual abrangendo esses conhecimentos de direita, esquerda, frente e traz, é possível analisar os objetos que rodeiam o espaço, onde o indivíduo está inserido.

Posteriormente, após essa exposição, os alunos foram convidados a responder algumas perguntas, envolvendo o diálogo ocorrido no primeiro momento da atividade. Conforme, os questionamentos foram apresentados para os alunos, evidenciou-se a participação dos mesmos no decorrer da atividade, além da demonstração do conhecimento, entrelaçados com as ideias que os estudantes já possuíam sobre o tema.

Convém destacar que, durante o desenvolvimento da atividade, observou-se que os alunos tinham conhecimentos prévios sobre a temática em relação com a mão que eles escrevem (direita ou esquerda). Dessa maneira, as perguntas realizadas foram de acordo com essa realidade, fazendo com que eles analisassem os objetos e colegas que estavam a sua direita e esquerda, pegando sempre como referencial o entendimento da mão deles, conforme a Figura 2. Diante disso, observou-se que a partir do questionamento se o colega estava a esquerda ou à direita, alguns alunos antes de responderem, acabavam olhando primeiramente para suas mãos.

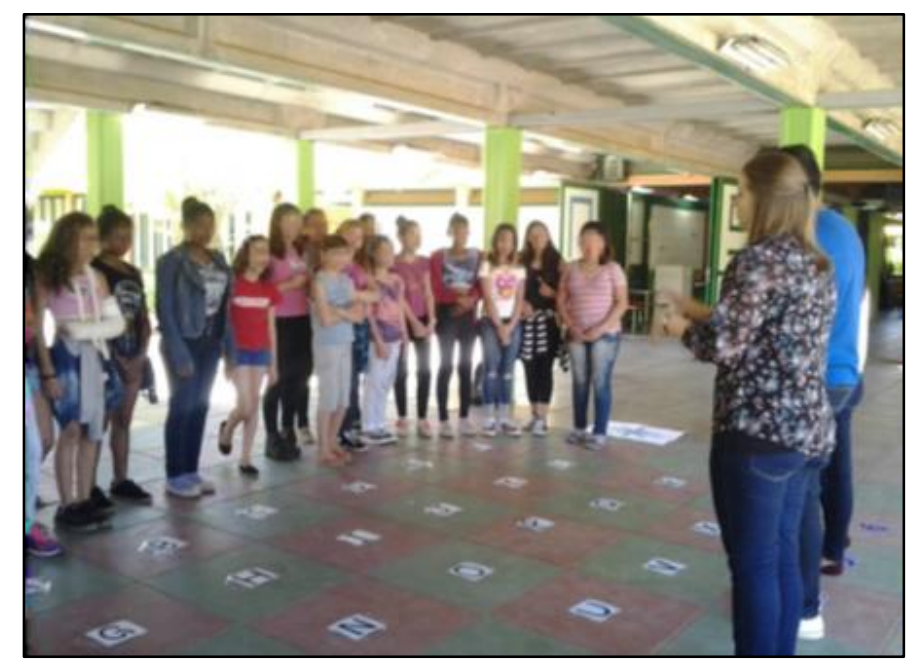

Figura 2 - Realização da prática sobre Lateralidade.

A segunda atividade, chamada de "Tabuleiro Vivo", foi introduzida com uma contextualização sobre meios de orientação e referenciais (bússola e GPS) com os discentes. Primeiramente, fora questionado e apresentado aos alunos alguns dos meios que o homem utiliza para se orientar e localizar no espaço. Após, transportou-se esses conhecimentos para uma rosa-dos-ventos, apresentando-lhes os pontos cardeais e colaterais. Para maior contribuição no entendimento e análise desses pontos, foi entregue a cada aluno uma pequena imagem das rosa-dos-ventos colada a uma cartolina. 
Com isso, foi realizado uma análise referente a qual direção fica o norte, sul, leste e oeste, em relação a escola, tendo como referencial o movimento aparente do sol. Durante essa teste com os alunos, notou-se que eles possuíam um certo domínio em entender essas orientações, bem como identificá-las em relação a estrutura física da escola.

A prática dessa atividade, os educandos atribuídos dos conhecimentos geográficos mencionados nas ocasiões anteriores, foram apresentados ao jogo "Tabuleiro Vivo". Para a realização desse jogo, os alunos foram divididos em dois grupos, a qual esses grupos deveriam competir entre si, trazendo além de uma prática escolar o espírito de competição e equipe entre os alunos, conforme o desenvolvimento da atividade.

O jogo foi montado sobre um tabuleiro desenhado na parte externa da escola. Para identificação de cada casa pertencente ao tabuleiro, foi confeccionado em cartolina todas as letras do alfabeto e números de 1 a 6 . Assim, esses números e as letras do alfabeto foram colados no tabuleiro para que servisse de referenciais sobre o andamento da atividade. A Figura 3 corresponde às letras e números confeccionados com finalidade de auxilio didático na atividade e o tabuleiro a qual foi aplicado a dinâmica

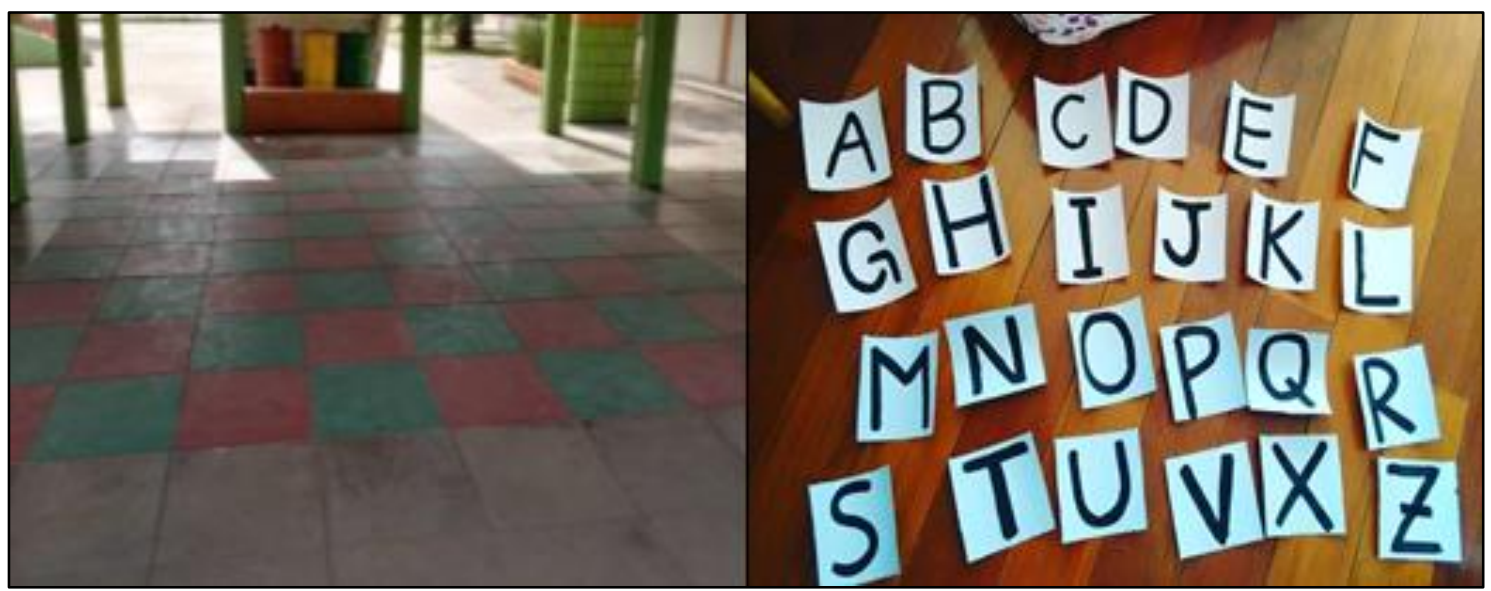

Figura 3 - Realização da prática sobre Lateralidade.

Para a realização da atividade prática, cada equipe recebeu cerca de dez cartelas, exemplificada na Figura 4, as quais indicavam um percurso que o aluno escolhido pela equipe deveria percorrer até chegar um ponto final. Essa cartela continha informações sobre Lateralidade e Orientação que o educando deveria obedecer, como por exemplo, "ande 2 casas a direita", "3 casas para norte". Assim, conforme o aluno realizava esses comandos, o mesmo chegava a uma casa final (letra ou número), onde que se estivesse certo, a equipe pontuava o desenvolvimento da atividade. 


\section{Partindo do ponto 4, ande:}

- 1 casa para a esquerda

- 3 casas para cima

- 2 casas para a direita

- 3 casas para baixo

- 1 casa para a direita

Onde você chegou?

\section{Partindo do ponto S, ande:}

- 5 casas para leste

- 1 casa para o sul

- 2 casas para noroeste

- 2 casas para norte

- 3 casas para oeste

Onde você chegou?

Figura 4 - Cartelas para o Jogo "tabuleiro vivo".

No decorrer da atividade, pode-se observar que os educandos sentirão motivados, participando ativamente em todo processo. Destaca-se por ser tratar de um jogo competitivo, a mesma ocasionou uma maior participação de todos educandos.

Em relação aos conceitos de Lateralidade e Orientação visto na prática dessa atividade, notou-se que alguns alunos tiveram dificuldade em resolver alguns percursos em relação aos pontos cardeais e colaterais, sendo necessário em certos momentos, relembrar uma contextualização desses pontos em relação à escola sobre o movimento do sol. No entanto, grande maioria dos discentes entendeu a proposta da atividade como também apresentaram domínio dos conteúdos trabalhados na ocasião da contextualização.

A dinâmica foi desenvolvida satisfatoriamente. Todavia, não foi encerrada como planejado, ou seja, com a participação de todos educandos, em razão do tempo e que alguns educandos estavam ansiosos para a próxima atividade, ocasionando certa dispersão em alguns momentos.

A terceira atividade foi um "Caça ao tesouro" pela escola, onde foi distribuído pelo pátio cinco bandeiras, essas identificadas pelas letras A, B, C, D e E. Para encontrar essas bandeiras as equipes deveriam interpretar um mapa da escola (Figura 5) que receberam, a qual essa imagem ilustrava a localização das pistas no pátio da escola. 


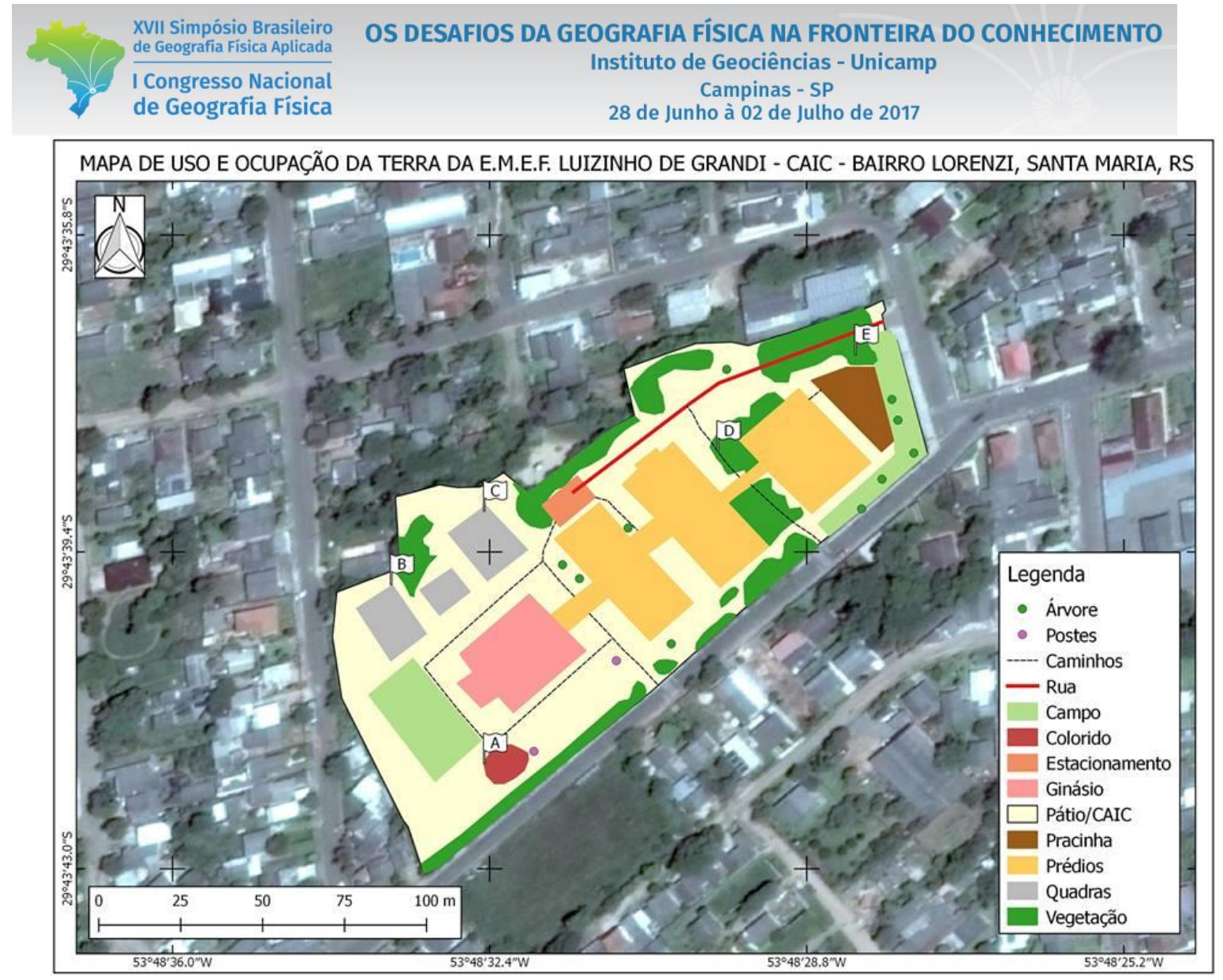

Figura 5 - Mapa da E.M.E.F. Luizinho de Grandi (CAIC) para o jogo "Caça ao tesouro"

Primeiramente, as equipes analisaram o mapa, bem como identificando os objetos pertencentes na escola na representação. Em seguida, as equipes dividiram seus integrantes em trios, a qual cada trio deveria ir um por vez, de acordo com o mapa, ao encontro das bandeiras, ou seja, o primeiro trio escalado a encontrar a bandeira A, o segundo a B, e assim sucessivamente até encontrar todas as bandeiras, tornando a equipe campeã a que fizesse toda atividade em menos tempo.

Convém destacar que conforme os alunos encontravam as bandeiras, nelas haviam números de 1 a 5 , a qual o trio deveria escolher um e trazer para o ponto de partida (Figura 6), e assim respectivamente de cada trio à sua bandeira. No final da prática, os alunos deveriam responder a um questionamento referente ao número escolhido em cada bandeira, essa pergunta abrangia os conceitos de Orientação geográfica, ou seja, de como os objetos estavam distribuídos na escola de acordo com os pontos cardeais/colaterais em relação a outros objetos, como por exemplo, "a bandeira A está a Norte, sul, leste, ou oeste do ginásio?", podendo consultar o mapa (figura 5) como ajuda.

Nessa atividade, observou-se total participação de todos alunos, a qual demonstraram motivados em realizar toda a atividade. Por se tratar de uma atividade lúdica, com teor competitivo, entrelaçando todo ambiente escolar pode-se observar que os educandos apresentaram domínio nos conhecimentos desenvolvidos pela Alfabetização Cartográfica, a saber Lateralidade e Orientação, como também facilidades na interpretação do mapa da escola, valorizando o espaço vivido do aluno. 


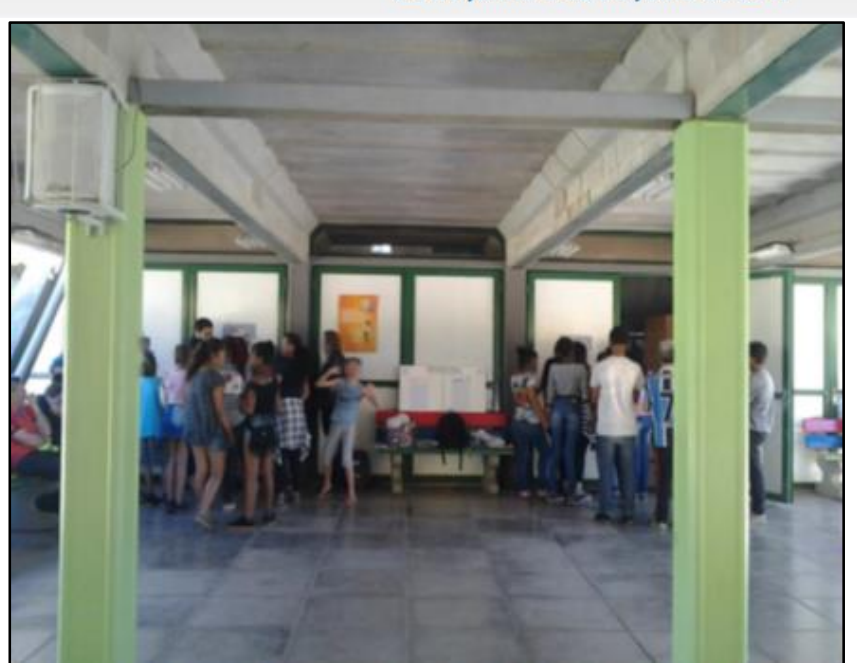

Figura 6 - Alunos analisando os mapas para a atividade "Caça ao tesouro".

\section{Considerações Finais}

Com o desenvolvimento dos processos metodológicos, pode observar que os educandos que participaram da Oficina foram assíduos demonstrando interesse em participar de todas atividades, bem como motivados tratando-se das contextualizações sobre Lateralidade e Orientação. No decorrer da oficina, notou-se a importância do ensino em Lateralidade e Orientação na geografia, visto que as mesmas tornam-se promissoras no auxílio ao homem e sua relação com os elementos presentes na superfície terrestre.

É possível inferir que o benefício realizar Oficinas didáticas na escola, enquanto aluno de graduação, é de todos os envolvidos, pois garante que os acadêmicos beneficiem-se da sua aprendizagem participando ativamente da organização da prática de ensino, bem como oportuniza aos escolares o contato com novas formas de aprender e vivenciar a aprendizagem colaborativa que estimulou os integrantes dos grupos a trabalharem conjuntamente para atingir metas.

\section{Agradecimento}

Agradecemos as colegas de disciplina Bruna Maltauro Tomazoni e Josiane Oliveira de Campos pela colaboração na aplicação da Oficina e a Escola Municipal de Ensino Fundamental Junto ao CAIC Luizinho de Grandi pela disposição em acolher a prática pedagógica realizada.

\section{REFERÊNCIAS}

FRANCISCHETT, M. N. Cartografia no ensino da geografia: construindo caminhos do cotidiano. Rio de Janeiro: Kro Art, 2002.

FREIRE, P. Pedagogia da autonomia: Saberes necessários à prática educativa. São Paulo: Paz e Terra, 1996.

PASSINI E. Y. Alfabetização Cartográfica e o livro didático: uma análise crítica. Belo Horizonte: Lê, 1994. 
RIZZATTI, M. Cartografia Escolar, Geotecnologias e a Teoria das Inteligências Múltiplas: a construção de conhecimentos geográficos no ensino fundamental. (Trabalho de Graduação) Universidade Federal de Santa Maria, Centro de Ciências Naturais e Exatas, Departamento de Geociências, Curso de Geografia - Licenciatura Plena, RS, 2016

SIMIELLI, M. E. R. Cartografia no ensino fundamental e médio. In: CARLOS, A. F. A. (Org.) A Geografia na sala de aula. São Paulo: Contexto, 1999.

SOUZA, V. L. C. A. A importância do letramento cartográfico nas aulas de Geografia. In: VI Congresso Latino Americano de Compreesão Leitora, 2013, Formosa. Anais do Congresso Latino Americano de Compreensão Leitora Jaime Cerrón Palomino, 2013. v. 6. 